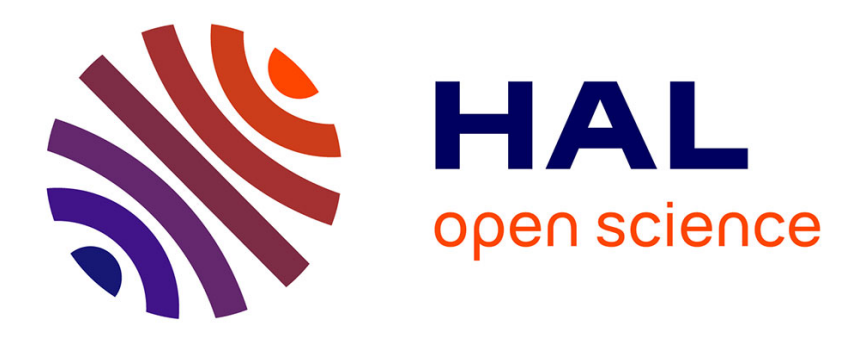

\title{
Centralized Innovation Policy in an agglomeration and growth model: A welfare analysis
}

Benjamin Montmartin

\section{To cite this version:}

Benjamin Montmartin. Centralized Innovation Policy in an agglomeration and growth model: A welfare analysis. 2011. halshs-00557484v2

\section{HAL Id: halshs-00557484 \\ https://shs.hal.science/halshs-00557484v2}

Submitted on 31 Jan 2011

HAL is a multi-disciplinary open access archive for the deposit and dissemination of scientific research documents, whether they are published or not. The documents may come from teaching and research institutions in France or abroad, or from public or private research centers.
L'archive ouverte pluridisciplinaire HAL, est destinée au dépôt et à la diffusion de documents scientifiques de niveau recherche, publiés ou non, émanant des établissements d'enseignement et de recherche français ou étrangers, des laboratoires publics ou privés. 
Centralized Innovation Policy in an agglomeration and growth model: A welfare analysis

Benjamin Montmartin

Janvier 2011 


\section{GATE Groupe d'Analyse et de Théorie Économique Lyon-St Étienne}

93, chemin des Mouilles 69130 Ecully - France

Tel. +33 (0)4 72866060

Fax $+33(0) 472866090$

6, rue Basse des Rives 42023 Saint-Etienne cedex 02 - France

Tel. +33 (0)4 77421960

Fax. $+33(0) 477421950$

Messagerie électronique / Email : gate@gate.cnrs.fr

Téléchargement / Download : http://www.gate.cnrs.fr - Publications / Working Papers 


\title{
Centralized Innovation Policy in an agglomeration and growth model: A welfare analysis
}

\author{
Benjamin Montmartin *
}

January 11, 2011

\begin{abstract}
Innovation policies are strategic tools for reinforcing long-term economic growth. If the literature highlights the need for coordination among national R\&D policies, the need for transnational policies appears to be less clear. Using a model à la Martin and Ottaviano (1999), we conduct a welfare analysis in order to judge the effect of a centralized R\&D subsidy policy. If theoretical results suggest that this policy can improve efficiency and equity, our welfare analysis shows that when there are few knowledge spillovers between countries, then the policy leads to a conflict of interest. In the case of strong international knowledge spillovers however, the conflict of interest disappears suggesting that innovation policies should first focus on the development of knowledge flows between countries.
\end{abstract}

JEL classification: $\mathrm{F} 43, \mathrm{H} 50, \mathrm{R} 12$

keywords: agglomeration and growth models, innovation policy, welfare criteria

\footnotetext{
*Université de Lyon, Lyon, F-69003, France; Université Jean Monnet, Saint-Etienne, F-42000, France; CNRS, GATE Lyon St Etienne, Saint-Etienne, F-42000, France, e-mail: benjamin.montmartin@univ-st-etienne.fr
} 


\section{Introduction}

Organization of the public sector is a crucial issue for all economies in order to improve the efficiency of public interventions. Indeed, every country can be viewed as an economic union of local jurisdictions. What is the best division of powers and budgetary resources between the different levels of power within an economic union? The Traditional Theory of Fiscal Federalism (Tiebout (1956), Musgrave (1959), Oates (1972)) investigates this question and shows that central government should be responsible for redistributive and macroeconomic stabilization policies as well as for public goods which provide services to the whole population of the country. The main justification for the decentralized levels of government are the provision of public goods and services, the consumption of which is limited to their own jurisdiction. The result of this is the so called Decentralized Theorem (Oates, 1972) which explains that by tailoring outputs of local public goods to the particular preferences and circumstances of their constituencies, local government provision increases economic welfare beyond that which results from the more uniform levels of such services that are likely to occur with national provision. The New Fiscal Federalism Theory puts the Decentralized Theorem into perspective by showing that in the case where local governments in the Economic Union have soft budget constraints, this may lead to situations of excessive debt and sub-optimal allocation of resources. The reason is that local governments can exploit the fiscal commons by shifting the burdens of local programs onto the economic union as a whole. Nevertheless, according to Besley and Coate (2003, p.2628) "the key insight remains that heterogeneity and spillovers are correctly at the heart of the debate about the gains from centralization" which are those highlighted by the Traditional Theory of Fiscal Federalism.

In the case of the European Union, the Decentralized Theorem is partially applied as some policies, which exceed the bounds of national interest like trade, industrial or agricultural policies, are coordinated at the EU level. Others however, which also affect the whole EU economy and generate externalities, remain decided and implemented by national authorities without real coordination. We obviously consider innovation policies ${ }^{1}$ which aim to strengthen the competitiveness of an economy and which are often considered to be of vital importance for long-term economic growth. Thus, it appears important to understand why innovation policies are mainly implemented by national authorities without coordination within the EU. Is it because policymakers consider knowledge and innovation as national public goods? Is it because of the specific characteristics of innovative activities that make centralized policies inefficient or for other reasons? The aim of this paper is not to directly address these questions but

\footnotetext{
${ }^{1}$ as highlighted by the European Commission (2000), "the principal reference framework for research activities in Europe is national"
} 
rather to provide a new enlightenment that may partially explain the specific organization of R\&D policies within the European Union.

Although there is substantial literature suggesting the need of $R \& D$ policies which would correct market inefficiencies, much less attention is paid to the specific question of the rationale for transnational R\&D policy coordination within an economic union. This question however is becoming increasingly important because, as highlighted by Kuhlmann (2001), many indicators show a growing process of internationalization of innovation activities due to the growing complexity of the knowledge required. Among them we can note the increasing volume of cross-border technology transfer via cooperation and strategic alliances in R\&D activities as well as the increasingly global organization of the $R \& D$ activities of multinational firms. In this context, it appears necessary to coordinate national R\&D policies in order to improve their global efficiency. More theoretically, the first contributions analyzing R\&D policies in an imperfectly competitive market with knowledge spillovers between firms (D'Aspremont and Jacquemin, 1987) show that cooperation in the R\&D stage of production is welfare enhancing. Later, Haaland and Kind (2006) show that in an R\&D subsidy game without spillovers between two producer countries (belonging to the same economic union), the uncoordinated outcome leads to inefficient levels of subsidies which can be corrected if R\&D policies are completely coordinated.

Chu (2009), using an open-economy growth model with technological spillovers, analyzes the growth and welfare effects of an R\&D subsidy policy according to different public authority organizations. He, like Haaland and Kind (2006), shows that the optimum is reached when the two countries cooperate. He also models the case where the two countries form an economic union in which the R\&D policy is managed by the central government but each national government chooses their own optimal level of R\&D expenditure. In this case, the equilibrium tax rate and the level of public $R \& D$ investment are higher than the optimum so that there is an overprovision of R\&D spending. This is due to the fact that in such an economic union there is a common-pool effect in which each region will try to externalize the tax burden of its research spending to the other country (c.f new fiscal federalism theory). Moreover, if the growth rate in the economic union is higher than in the cooperative case, it is the opposite concerning the welfare. The author also shows that there is a critical value of international knowledge spillovers above (below) which the welfare associated with a centralized R\&D policy at the economic union level is higher (lower) than those associated with non cooperative $R \& D$ policies.

Therefore, although empirical and theoretical results converge towards the idea that R\&D policies in an economic union should be coordinated, the effectiveness of centralized $R \& D$ policies does not appear as obvious due to the strategic 
behavior of national governments ${ }^{2}$. We can however, easily find arguments in favor of directly establishing of R\&D policies at a transnational level. For instance, in some specific fields of research that concern all countries and need a high critical mass of $R \& D$ inputs, this can be more efficient when implemented at a transnational level.

In this paper, we take a different approach to the papers presented above by using an agglomeration and growth model à la Martin and Ottaviano (1999). We use this framework as it realizes a synthesis between the endogenous growth model à la Romer (1990) and the New Economic Geography model à la Martin and Rogers (1995) thereby allowing us to take income, growth and spatial effects into account. Moreover, this framework is appropriate for the European context. Indeed, we assume a world composed of two countries with different levels of wealth in which capital is perfectly mobile and labor is immobile. This framework has already been used by Martin (1999), Riou (2003) and Montmartin (2010) to analyze the effects of public policies. Concerning innovation policies, the common result is that such policies can reach objectives of both higher efficiency and equity ${ }^{3}$. Thus, we will try to highlight some reasons which could explain why such policies achieving both the European Commission objectives are so difficult to implement at the European level. Indeed if some R\&D policies like Framework Programs or the new Regional Policy are implemented at the European level, they represent a very small proportion of public $R \& D$ expenditure in the European Union. Moreover, as is highlighted by Brehon (2010), the richer countries or the so-called austerity coalition ${ }^{4}$ try to impose limits during each European budget negociation.

To explain these facts, we investigate the optimality of a centralized subsidy policy for R\&D employment according to four different welfare criteria and different levels of economic integration ${ }^{5}$. Our results suggest that whatever the level of economic integration, if the central government priority is to increase global welfare or to improve the situation of the poorest country, then the central authority has to implement an important R\&D subsidy policy. Based on the

\footnotetext{
${ }^{2}$ As Chu (2009) has noted "In the EU, although the research priorities of the Framework Program are not chosen directly by any national government, the member states may influence the European Parliament and the council through interest groups. As the study by the European Institute of Romania suggests, this process of political negotiations could lead to an unnecessary increase in the number of research priorities".

${ }^{3}$ Note that Montmartin (2010) shows that this is true only if the innovation policy does not change the geography of innovative activities.

${ }^{4}$ This coalition refers to the six European members (Germany, France, United Kingdom, Austria, Sweden and the Netherlands) who signed the "lettre des six" in 2003. In this letter, these countries expressed their concern about budget proposals made by the European Commission (considered as too high) and argued in favor of a budget limit set at $1 \%$ of the European GDP.

${ }^{5}$ In this paper, we define economic integration as trade integration as well as knowledge integration, i.e, the capacity of a country to access knowledge produced in other countries.
} 
idea however, that the central decision for this policy is the result of political negotiations with national authorities, we propose a new welfare criterion taking global as well as individual considerations into account. In our point of view, this is a better reflection of the constraints and/or the necessary conditions for implementing central policies in the European Union. According to this welfare criterion, we show that in the case where international knowledge spillovers are low or at an intermediate level, then the optimum is obtained when the central government does not implement the policy. The reason is that this policy will increase the welfare of the poorer country but will also reduce the welfare of the richer country who is the major financial backer. This therefore leads to a conflict of interest between regions. The only case where the implementation of a centralized $R \& D$ policy is optimal (according to this welfare criterion) is when the international knowledge spillovers are high. This result is consistent with those of Chu (2009) who shows that the implementation of an R\&D subsidy policy by a supranational government improves welfare compared to the non cooperative case if international knowledge spillovers are high. In any case, our result is able to partially justify the behavior of richer countries towards European R\&D policies and especially towards the Regional Policy ${ }^{6}$. Indeed, we could reasonably assume that international knowledge spillovers are not really high among European countries due to frequent knowledge transfer barriers, as evidenced by empirical studies (see for instance Maurseth and Verspagen, 2002). Consequently, to facilitate the establishment of a centralized R\&D policy in the EU, our main recommendation is that European policies should first focus upon the strengthening and development of knowledge flows between European countries.

This paper is organized as follows. In the next section, we present the general framework. Section 3 presents our assumptions concerning the innovation process and defines the steady state of our economy. After having briefly recalled the effects of an innovation policy on the equilibrium outcome, section 4 proposes a welfare analysis of such a policy. Section 5 discusses the results and brings them into perspective.

\section{The framework}

The general framework is based upon Martin and Ottaviano (1999). The economy is composed of two countries $a$ and $b$, two factors of production ( $L$ and $K)$, three private sectors $(T, M$ and $I)$ and one public sector. The labor (L) endowment of each country is fixed and equal to $L$ whereas the knowledge capital (K) is produced by the Innovative sector (I). Contrary to the knowledge capital which is supposed to be perfectly mobile, labor is geographically immobile but sectorially mobile.

\footnotetext{
${ }^{6}$ see Mesclier (2007), chapter 2, p.138 for details
} 
I-sector is perfectly competitive and produces one unit of $K$ with $a_{I}$ units of $L$. I-Firms sell blueprints of variety to Manufacturing firms $(M)$ with a infinitelived patent which gives them a perpetual monopoly rent. M-firms face DixitStiglitz monopolistic competition and increasing returns. Each differentiated variety is produced by a single M-firm using $\beta$ units of $L$ and one unit of $K$. The Traditional sector $(T)$ is perfectly competitive and produces an homogeneous good using one unit of $L$. Trade in M-varieties is subject to Iceberg cost whereas trade is costless in the T-sector. Finally, in our model the public sector has a merely redistributive role, i.e, it can tax the monopoly rent of $\mathrm{M}$-firms $^{7}$ to subsidize employment in the I-sector. Here, we assume that the government does not geographically differentiate the tax rate or the level of subsidy such that $T=T_{a}=T_{b}$ and $S=S_{a}=S_{b}$, i.e, the tax rate on M-firms as well as the level of subsidy per unit of labor used in R\&D are the same in both countries. In what follows, we assume that the T-sector is active in both countries at the equilibrium. Using the homogeneous good as numeraire, the wage rate and the price of this good are equal to one. We summarized the basic structure of the model in figure 1 below.

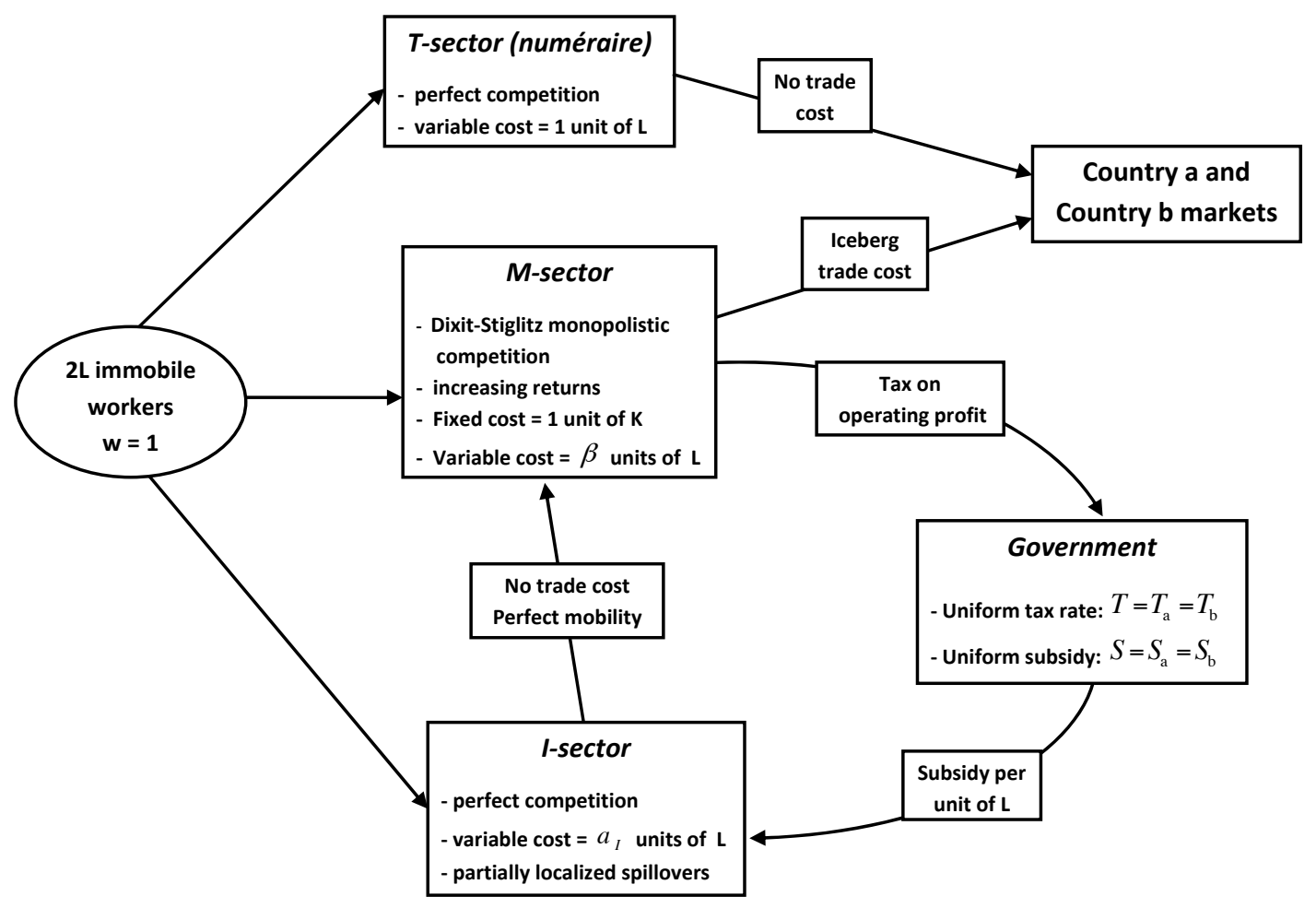

Figure 1 : Basic structure of the model

\footnotetext{
${ }^{7}$ Note that in our model a proportional tax on the operating profit of M-firms is equivalent to a tax on GDP to within one constant (see Montmartin (2010)).
} 


\subsection{Consumption and production}

Let $N_{w}$ be the number of differentiated varieties available in the economy. Consumer preferences are given by a Cobb-Douglas utility function and intertemporal CES function with unit elasticity of intertemporal substitution:

$$
\int_{0}^{\infty} \ln \left[D(t)^{\alpha} H(t)^{1-\alpha}\right] e^{-\rho t} d t
$$

where $H$ is the consumption of the homogeneous good, $\rho \in[0 ; 1]$ is the time preference and $\alpha \in[0 ; 1]$ represents the share of expenditure devoted to the consumption of differentiated goods. Demand for differentiated goods in country $a$ is represented by a CES function à la Dixit-Stiglitz (1977):

$$
D_{a}(t)=\left[\int_{0}^{N_{a}} D_{a}^{a}(t)^{\frac{\sigma-1}{\sigma}} d a+\int_{0}^{N_{b}} D_{a}^{b}(t)^{\frac{\sigma-1}{\sigma}} d a\right]^{\frac{\sigma}{\sigma-1}}
$$

$N_{a}\left(N_{b}\right)$ denote the number of varieties produced in region $a(b)$ such that $N_{w}=$ $N_{a}+N_{b}$ and $\sigma$ represents the elasticity of substitution between varieties as well as the price elasticity of demand for each variety. The expenditure of a representative consumer located in country $a$ is given by:

$$
E_{a}(t)=\left[\int_{0}^{N_{a}} D_{a}^{a}(t) P_{a}^{a} d a+\int_{0}^{N_{b}} D_{a}^{b}(t) P_{a}^{b} d a+P_{H} H_{a}\right]
$$

$D_{a}^{a}$ and $D_{a}^{b}$ are the demands for a variety produced in country $a$ and $b$ of a consumer located in $a . P_{a}^{a}$ and $P_{a}^{b}$ are prices of the i-th variety produced in $a$ and $b$. In what follows we leave implicit the dependence of variables on time except for initial variables subscripted by 0 .

Consumers solve their maximization problem in two separate steps. First, consumer maximizes his utility (1) with respect to his budget constraint (3). For a representative consumer located in country $a$, we have:

$$
\begin{gathered}
H_{a}=(1-\alpha) E_{a} \\
D_{a}^{a}=\frac{\alpha E_{a}\left(P_{a}^{a}\right)^{-\sigma}}{\Delta} \quad D_{a}^{b}=\frac{\alpha E_{a}\left(P_{a}^{b}\right)^{-\sigma}}{\Delta} \\
\Delta=\int_{0}^{N_{a}}\left(P_{a}^{a}\right)^{1-\sigma}+\int_{0}^{N_{b}}\left(P_{a}^{b}\right)^{1-\sigma}
\end{gathered}
$$

Second, the representative consumer achieves an intertemporal trade off between consumption and saving. As in Grossman and Helpman (1991, chp.3), saving takes place in the form of a riskless asset that pays an interest rate $r$ or 
in the form of investment in shares of $\mathrm{M}$-firms on a world stock market ${ }^{8}$. By this market, M-firms finance their unit of knowledge capital required to produce. Therefore, individual income is composed of the wage rate equal to one and of the investment returns in M-firms. Some shares of M-firms endowment or knowledge capital $K_{a}(0)$ and $K_{b}(0)$ are assumed to be owned by consumers from the start with an inequality such that:

$$
K_{a}(0)>K_{b}(0)
$$

This initial asymmetry will lead to an income and expenditure inequality between countries. The free capital mobility hypothesis ensures a symmetric yield of shares and therefore the incentives to accumulate capital are the same in both countries. This implies that the share of knowledge capital owned by each country is stable over time and given by the initial distribution (6).

In this second step, the consumer maximizes his utility (1) with respect to his intertemporal budget constraint which is given by:

$$
\dot{z}=w+r z-E_{a}
$$

where $z$ is the value of the assets' stock of a representative consumer. Solving the Hamiltonian, we obtain the Euler equation for the evolution of expenditure:

$$
\frac{\dot{E_{a}}}{E_{a}}=r-\rho
$$

The growth rate of individual expenditure in country $a$ is equal to the difference between the interest rate and the rate of time preference. Note that as consumers' preferences are the same in both countries, the growth rate of expenditure is also the same.

On the supply side, M-firms have the same technology and we assume that the tax rate is the same in both regions ${ }^{9}$, so we can write the post-tax operating profit of an M-firm located in country $a$ as:

$$
\Pi_{a}=\left[\left(P_{a}^{a} D_{a}^{a}+P_{b}^{a} D_{b}^{a}\right)-\beta\left(D_{a}^{a}+\tau D_{b}^{a}\right)\right] L(1-T)
$$

As trade in M-varieties is subject to lceberg cost, $\tau>1$ units must be shipped to sell one unit abroad which explains why M-firms have to produce $\tau D_{b}^{a}$ to meet foreign demand. Maximization of profit implies that M-firms mark up price over marginal cost by a factor of $\sigma /(\sigma-1)$. Using a corresponding expression of (8) for country $b$, the optimal pricing policy of $\mathrm{M}$-firms is given by:

$$
P_{a}^{a}=P_{b}^{b}=\frac{\beta \sigma}{\sigma-1} \quad P_{b}^{a}=P_{a}^{b}=\frac{\tau \beta \sigma}{\sigma-1}
$$

\footnotetext{
${ }^{8}$ In this kind of model, firm shares are riskless assets because they will reflect the real value of firms. This is due to the fact that we remove the case of a speculative bubble.

${ }^{9}$ This hypothesis reflects the fact that most of the EU budget comes from a uniform tax applied to the GDP of each member.
} 
As firms' and consumers' behavior is the same in both regions, we can rewrite the operating profit of a firm located in region $a, b$ as:

$$
\Pi_{a, b}=\frac{\beta x_{a, b}}{\sigma-1}(1-T)
$$

where $x_{a, b}$ represents the total production of a firm located in country $a, b$.

\subsection{Location equilibrium of the industrial sector}

In a first step, we introduce optimal prices (9) in demand functions (5) to obtain optimal demands of a consumer located in region $a$ :

$$
D_{a}^{a}=\frac{\sigma-1}{\beta \sigma} \frac{\alpha E_{a}}{N_{a}+\phi N_{b}} \quad D_{a}^{b}=\frac{\sigma-1}{\beta \sigma} \frac{\alpha E_{a} \tau^{-\sigma}}{N_{a}+\phi N_{b}}
$$

where $\phi=\tau^{1-\sigma}$ represents the level of trade integration. Following Martin and Rogers (1995), $\tau$ is related to the quality of transport infrastructures. A reduction of $\tau$ corresponds to an improvement of transport infrastructures and therefore to an increase of $\phi(d \phi / d \tau<0)$.

We now have to define the condition which ensures equilibrium on the differentiated goods market. Using expressions (11) and corresponding expressions for region $b$, we obtain the level of production in each country:

$$
\begin{aligned}
& x_{a}=\frac{\alpha L(\sigma-1)}{\beta \sigma N_{w}}\left(\frac{E_{a}}{\left[s_{n}+\phi\left(1-s_{n}\right)\right]}+\frac{\phi E_{b}}{\left[\phi s_{n}+\left(1-s_{n}\right)\right]}\right) \\
& x_{b}=\frac{\alpha L(\sigma-1)}{\beta \sigma N_{w}}\left(\frac{\phi E_{a}}{\left[s_{n}+\phi\left(1-s_{n}\right)\right]}+\frac{E_{b}}{\left[\phi s_{n}+\left(1-s_{n}\right)\right]}\right)
\end{aligned}
$$

where $s_{n}=N_{a} / N_{w}$ is the share of M-firms located in country $a$. With perfect capital mobility, location equilibrium must satisfy the condition of equality of post tax operating profit. Indeed, for a constant share of manufacturing firms $\left(s_{n}\right)$ exists, M-firms must have no incentives to relocate their production, i.e, $\Pi_{a}(1-T)=\Pi_{b}(1-T)$. Using equations (12) and (13), we get:

$$
s_{n}=\frac{s_{e}-\phi\left(1-s_{e}\right)}{(1-\phi)}
$$

where $s_{e}=E_{a} / E_{w}$ is the share of expenditure and income held by consumers located in country $a$. Note that the higher the trade integration, the higher the concentration of M-firms in the richer country. Finally, we can establish the equilibrium production of $\mathrm{M}$-firms for a given level of expenditure by introducing (14) in (12):

$$
x=\alpha L \frac{\sigma-1}{\beta \sigma} \frac{E_{w}}{N_{w}}
$$


Expression (15) corresponds to the optimal production of all M-firms (regardless of their location).

\section{Innovation Production Function, location of R\&D and the steady state}

\subsection{Innovation process and knowledge externalities}

In this model, the innovation sector works as in Grossman and Helpman (1991, chap.3). Innovation corresponds to the increase in the number of available M-varieties and is a constant returns to scale activity for individual firms. It produces however, increasing external returns to scale. In order to produce one unit of knowledge capital, researchers must use $a_{I}$ units of labor. Following Romer (1990), we assume that $a_{I}$ follows a learning curve, i.e, the marginal cost of one unit of knowledge capital decreases gradually as the number of M-firms increases (R\&D productivity increases with the number of M-firms). Therefore, knowledge spillovers are transmitted from production to design. Moreover, we make the assumption as Baldwin and al. (2001) that these knowledge externalities are partially localized. This implies that a country's production cost for knowledge capital depends negatively on the number of national M-firms and to a lesser extent on the number of M-firms located in the other country. It refers to the idea that intranational spillovers or Marshall-Arrow-Romer externalities (Glaeser and al., 1992) are stronger than international spillovers that are transmitted by trade for instance (Feldman, 2000). This assumption is directly related to the stylized fact that knowledge spillovers are geographically bounded and decrease as geographical distance increases.

Central government uses the tax revenue to subsidy I-firms. More specifically, we assume that it gives a subsidy per unit of labor employed in $R \& D{ }^{10}$. In this paper, we only consider the case where the government does not differentiate the level of subsidy according to regions $\left(S_{a}=S_{b}=S\right)$. Two reasons explain this choice. Firstly, if the subsidy policy is undifferentiated then the location of innovative firms is not affected at the equilibrium which simplifies the analysis ${ }^{11}$. Secondly, it is more interesting to highlight some issues in the best case, i.e, when the subsidy policy has the higher positive effects on the economy than when the subsidy policy is differentiated (see Montmartin, 2010).

We can summarize these assumptions by the following innovation production function:

\footnotetext{
${ }^{10}$ The main justification for this choice is technical as a subsidy on the total cost of innovation would render the model unstable.

${ }^{11}$ see Montmartin (2010) for a geographically differentiated subsidy policy.
} 


$$
\begin{gathered}
\dot{K}_{w}=\frac{L_{I}}{a_{I}}=\frac{L_{I}^{a}}{a_{I}^{a}}+\frac{L_{I}^{b}}{a_{I}^{b}} \\
a_{I}^{a} \equiv \frac{1}{K_{w} A_{a}} \quad a_{I}^{b} \equiv \frac{1}{K_{w} A_{b}} \\
A_{a}=s_{n}+\lambda\left(1-s_{n}\right) \quad A_{b}=\lambda s_{n}+1-s_{n}
\end{gathered}
$$

where $a_{I}^{a}$ and $a_{I}^{b}$ represent the productivity of $\mathrm{R} \& \mathrm{D}$ in regions $a$ and $b, A_{a}$ and $A_{b}$ represent knowledge externalities for I-firms located in country $a$ and $b$, $L_{I}^{a}$ and $L_{I}^{b}$ are the quantity of labor employed in R\&D in regions $a$ and $b$ and $\lambda \in[0,1]$ is the level of international knowledge spillovers, i.e, the geographical scope of knowledge spillovers. Using (16) and the fact that the wage rate is equal to one, we can write the cost of producing one unit of knowledge capital in countries $a$ and $b$ as:

$$
F_{I}^{a}=\frac{1-S}{K_{w} A_{a}} \quad F_{I}^{b}=\frac{1-S}{K_{w} A_{b}}
$$

where $S$ represents the amount of subsidy per unit of labor employed in R\&D activities. Note that R\&D activities will only locate in both regions when the cost of producing one unit of knowledge capital is the same. With imperfect international knowledge spillovers $(\lambda<1)$, it is less costly to locate in the country with the highest number of M-firms. As $K_{a}(0)>K_{b}(0)$, the income of consumers in country $a$ is higher than in country $b$ for all $t$ because initial endowments represent pure rents. Therefore, more M-firms locate in country $a$, see (14), thereby rendering R\&D productivity higher in this country. Consequently, the whole I-sector will locate in the richer country to benefit from higher knowledge spillovers. Thus, the cost of innovation for l-firms is given by $F_{I}=F_{I}^{a}$.

In order to express the level of subsidies, we have to find the world labor demand for R\&D activities using expressions (16):

$$
L_{I}=\frac{g}{A}
$$

where $L_{I}$ is the world quantity of labor employed in R\&D activities, $g$ is the aggregate growth rate and $A=A_{a}$.

In this model, we assume that the government has a balanced budget constraint. The rule of balanced budget for the government is satisfied when the tax income is equal to expenditure. The government tax revenue is the sum of taxes collected from the $N_{w} \mathrm{M}$-firms which corresponds to $T$ times the tax base:

$$
R=T \frac{\alpha L E_{w}}{\sigma}
$$


Total government expenditure is simply equal to the quantity of labor employed in R\&D multiplied by the amount of the subsidy:

$$
T E=L_{I} S
$$

Using these expressions and (17), we can express the level of subsidy satisfying the balanced budget constraint as:

$$
S=T \frac{\alpha L A E_{w}}{\sigma g}
$$

\subsection{Labor market equilibrium and the growth rate}

\subsubsection{Labor market}

As the labor is sectorially mobile, it will be used in all three private sectors of the economy. The world labor supply is fixed and equal to $2 L$. Labor demand in the T-sector is obtained from (4). The quantity of labor used in the Msector corresponds to the product of the individual production of firms (15), the number of M-firms $\left(N_{w}\right)$ and the marginal need for labor $(\beta)$. Labor demand in the I-sector is simply given by (17). Therefore, the equilibrium condition for the labor market is:

$$
2 L=\frac{g}{A}+L_{e} E_{w}\left(\frac{\sigma-\alpha}{\sigma}\right)
$$

As the labor supply is a constant, an equilibrium exists if and only if the demand for labor is also constant. Note that in (19), all terms are parameters excepting $E_{w}$. Thus, $E_{w}$ has to be constant over time to have an equilibrium. This condition is crucial as according to (7), this implies:

$$
r=\rho
$$

Expression (20) means that the interest rate of riskless assets is constant and equal to the rate of time preference.

\subsubsection{The equilibrium growth rate}

The equilibrium growth rate is derived from the incentives to innovate. This requires the traditional condition of no opportunity for arbitrage between investing in R\&D and borrowing at the safe rate $r$. Call $v(t)$ the stock market value of a M-firm. This value corresponds to the present discounted value of its post tax operating profit. That is,

$$
v(t)=\int_{t}^{\infty} e^{-[R(s)-R(t)]} \frac{\beta x(s)}{\sigma-1}(1-T) d s
$$


where $R(t)=\int_{0}^{t} r(u) d u$ is the cumulative discount factor applicable to profits earned from the period 0 to $t$. Differentiating (21) with respect to time gives us the no arbitrage condition which has to hold at every moment in time in order to ensure stock market equilibrium:

$$
\dot{v}+\frac{\beta x}{\sigma-1}(1-T)=r v
$$

With conditions of free entry and zero profits in the l-sector, the value of a firm is equal to the price of one unit of knowledge capital, i.e, the marginal cost of innovation $F$. With a wage rate equal to one, we have the following equality at the equilibrium:

$$
F=v=\frac{(1-S)}{K_{w} A}
$$

At the steady state, $A$ and $(1-S)$ are constants. We can therefore easily calculate the growth rate of a firm's value:

$$
\frac{\dot{F}}{F}=\frac{\dot{v}}{v}=-g
$$

The growth rate of the firm's value is equal to the inverse of the growth rate of new varieties; the reason being that an increase of the growth rate means that more firms enter in the market. This increases the competition in the $\mathrm{M}$ sector thereby reducing individual profit. The value of a firm being the present discounted value of its profit, it follows that the value of a firm decreases when growth is positive. Substituting (15), (20), (23), (24) in (22), we can express the no arbitrage condition as:

$$
\frac{\alpha L E_{w} A(1-T)}{\sigma(1-S)}=\rho+g
$$

To obtain the equilibrium growth rate, we have to substitute the expressions (18) and (19) in (25). We have to find the solution of a second degree polynomial function in $g$. There are two solutions but we are most interested in the case where the growth rate is positive, that is:

$$
\begin{gathered}
g= \begin{cases}\frac{\Lambda+\sqrt{\Lambda^{2}+8 \alpha \sigma \rho A L T}}{2 \sigma} & \text { si } T \in[0,1[ \\
-\rho & \text { otherwise }^{12}\end{cases} \\
\Lambda=\alpha[2 A L-\rho T]-\rho(\sigma-\alpha)
\end{gathered}
$$

\footnotetext{
${ }^{12}$ When the tax rate is equal to one, the growth rate is negative; the reason being that, if the government taxes all profits, M-firms cannot give owners a dividend. Therefore, no consumer will invest in M-firms and the no arbitrage condition (26) is satisfied for $g=-\rho$. The government will therefore never fix the tax rate at one.
} 
Expression (26) tells us that a higher spatial concentration of M-firms in country $a$ will lead to a higher aggregate growth rate. The reason is simply that the spatial concentration of the industrial sector in the richer country increases $R \& D$ productivity which in turn increases the incentives to innovate and hence the growth rate. Note also that parameters $\lambda, \alpha$ and $L$ have a positive effect on growth whereas parameters $\sigma$ and $\rho$ have the opposite effect. In economic terms, this means that a wider dissemination of knowledge between countries and a "more innovative economy" (a higher differenciation of products and a higher consumption of these goods) lead to a higher growth rate.

\subsection{Income inequality and the steady state equilibrium}

\subsubsection{Income inequality and growth}

To obtain the steady state of the model, we have to define a last equilibrium relation. We have already defined how the equilibrium location of M-firms $\left(s_{n}\right)$ is determined by expenditure inequality (14) and how the equilibrium growth rate $g$ depends on $s_{n}(26)$. The last relation defines the income and expenditure inequality as a function of $g$. We know that in both regions nominal expenditure and income of consumers are stable at the steady state. The consumer's income is the sum of his labor income plus his capital income. Concerning labor income, each worker perceives a salary equal to one at each period. Concerning capital income, it should be noted that in both regions, the consumers' capital stock grows at rate $g$ and the value of one unit of capital decreases at rate $g$. Thus, the value of capital income is stable over time. The consumer will then consume his labor income and $\rho$ times the value of the initial per-capita stock of assets as only the profits of this initial stock are pure rents. The income and expenditure of a representative consumer are therefore given by:

$$
E_{a}=1+\frac{\rho K_{a}(0) v(0)}{L} \text { et } E_{b}=1+\frac{\rho K_{b}(0) v(0)}{L}
$$

Inserting (23), we can rewrite these expressions as

$$
E_{a}=1+\frac{\rho s_{k}(1-S)}{L A} \text { and } E_{b}=1+\frac{\rho\left(1-s_{k}\right)(1-S)}{L A}
$$

Using expressions (19) and (26) and inserting them into expressions (27), we can express the equilibrium relation between the income inequality $\left(s_{e}\right)$ and the growth rate $(g)$ :

$$
s_{e}=\frac{1}{2}+\frac{\alpha \rho\left(2 s_{k}-1\right)(1-T)}{2 \sigma(g+\rho)}
$$

where $s_{k}=K_{a} / K_{w}$ represents the share of world capital stock owned by consumers located in country a. Note that, as long as $s_{k}>1 / 2$ and $T<1$, the 
nominal income is higher in country $a$ than in country $b$. Moreover, it should be noted that the income and expenditure gap decreases in $g$; the reason being that a higher growth rate implies higher competition in the $\mathrm{M}$-sector and therefore a reduction of individual profit. It should be remembered that the value of a firm is the present discounted value of its profits. As income from capital is a more important part of total income in country $a$ than in country $b$, the fall in the firm's value will have a higher impact on consumers in country $a$. For this reason, the income inequality between countries decreases with the growth rate.

\subsubsection{The steady state}

To close the model, we have to define the equilibrium location of M-firms and the growth rate at the steady state. Inserting expressions (26) and (28) in (14), we get the following equilibrium relation:

$$
\begin{gathered}
s_{n}=\frac{1}{2}+\frac{\alpha \rho(1-T)\left(2 s_{k}-1\right)}{\rho(\alpha+\sigma)+\sqrt{\Lambda^{2}+8 A L T \alpha \sigma \rho}+\alpha(2 A L-\rho T)}\left(\frac{1+\phi}{1-\phi}\right) \\
\text { with } A=s_{n}+\lambda\left(1-s_{n}\right)
\end{gathered}
$$

We can rewrite (29) as $f\left(s_{n}\right): a s_{n}{ }^{3}+b s_{n}{ }^{2}+c s_{n}+d=0$. This implies that $s_{n}$ is the solution of a third degree polynomial function. The solution of this polynomial function is given in appendix A. To obtain the equilibrium growth rate, we have to replace the solution of (29) in expression (26).

\section{Subsidy policy for innovation, welfare and conflict of interest}

In this last section, our objective is threefold. Firstly, we will describe the impacts of the subsidy policy on the consumer's welfare in both countries. Secondly, we will investigate the optimality of such a policy according to different welfare criteria and levels of economic integration. Here, the notion of economic integration refers to the level of trade integration as well as the level of knowledge integration, i.e, the level of international knowledge spillovers. Thirdly, using welfare analysis, we highlight a conflict of interest between countries that could partly explain the difficulties in implementing such a policy at the European level.

\subsection{Effects of the innovation subsidy policy on growth and equity}

As the main objective of the European Commission is to promote a more sustained and balanced growth, we briefly recall the theoretical impact of an innovation policy upon growth and equity before analyzing its effects upon welfare. Using the same framework, Martin (1999) analyzed in partial equilibrium, 
different public policies implemented by the European Union. His results suggest that only a policy which reduces the cost of innovation is able to achieve both the European Commission's objectives. Other policies such as investment in transport infrastructures lead to a trade off between growth and equity.

Given the strategic shift of the New European Regional Policy (2007-2013) towards innovation and the fact that previous works are realized in partial equilibrium, Montmartin (2010) investigates the impacts of a subsidy policy to R\&D employment upon growth and equity taking funding issues into account, i.e, in general equilibrium. We refer the reader to this paper in order to have a complete analysis of this innovation subsidy policy. In what follows, we simply highlight the main mechanisms coming into play. Nevertheless, we give a proof of this result in appendix $B$.



Figure 2 : Main effects of the innovation policy on the equilibrium

If the government raises the tax rate on M-firms' profit then M-firms' value decreases. We know that a part of the consumer's wealth is composed of shares in M-firms so that the consumers' nominal income decreases. As a greater share of the consumers in country a's income is related to capital, the income inequality decreases, see (28). Furthermore, the increase in the tax rate allows the government to increase the level of the subsidy and therefore to decrease the cost of innovation so that the aggregate growth rate increases ${ }^{13}$. As we

\footnotetext{
${ }^{13}$ More exactly, the growth rate increases because the fall of the innovation cost is higher than the decrease of M-firms value so that the incentives to innovate increase.
} 
can see from equation (28), a higher growth rate will also decrease the income inequality. The location of industrial activities being directly related to income inequality, see (14), a decrease of income inequality leads some industrial firms to delocate from the richer country to the poorer. Thus, the subsidy policy for $R \& D$ employment will reduce the concentration of industrial activities as well as the income inequality and increase the aggregate growth rate. This would therefore lead to a more efficient and equitable economic equilibrium.

From the point of view of equity and growth, the central authority should implement the largest possible subsidy policy to $R \& D$ employment. The question then is to determine whether the result is the same where the consumer's welfare is concerned.

\subsection{Indirect utility and welfare criteria}

Grossman and Helpman (1991) showed that in models with monopolistic competition and horizontal product innovation, the market equilibrium is Paretoefficient if and only if there are no knowledge spillovers in the innovation production function. If however, we assume the presence of knowledge spillovers then the market equilibrium is sub-optimal from the point of view of the planner. Indeed, as current research has a positive spillover on the productivity of future research, a planner would engage in more $R \& D$ activity than the decentralized economy. But, as Martin and Ottaviano (1999) highlight, another distortion suggests that the spatial equilibrium concentration of industrial activities is not optimal. Indeed, investors do not take the positive impact of the spatial concentration on the aggregate growth rate into account when they decide where to invest their capital. Thus, the concentration of firms in the richer country is too low given that an increase of the concentration will increase the aggregate growth rate. In other words, with knowledge spillovers, the Pareto-efficient equilibrium corresponds to a higher growth rate associated with a higher concentration of manufacturing firms than the market outcome. It should be remembered that the implementation of the innovation subsidy policy will lead to a reduction of industrial sector concentration compared to the market outcome. Consequently, we already know that the innovation subsidy policy will lead, in the best case, to a second best allocation.

We measure individual welfare using the indirect utility of consumers. Call $V_{a}$ and $V_{b}$ the indirect utility of a representative consumer in countries $a$ and $b$. Using equations (1), (4), (5) and (27), we obtain the following expressions:

$$
\begin{aligned}
V_{a} & =\frac{1}{\rho} \log \left[C\left(1+\frac{\rho s_{k}(1-S)}{L A}\right)\left(s_{n}(1-\phi)+\phi\right)^{\frac{\alpha}{\sigma-1}} e^{\left.\frac{\alpha g}{\rho(\sigma-1)}\right]}\right. \\
V_{b} & =\frac{1}{\rho} \log \left[C\left(1+\frac{\rho\left(1-s_{k}\right)(1-S)}{L A}\right)\left(1-s_{n}(1-\phi)\right)^{\frac{\alpha}{\sigma-1}} e^{\frac{\alpha g}{\rho(\sigma-1)}}\right]
\end{aligned}
$$


with

$$
C=\alpha^{\alpha}(1-\alpha)^{1-\alpha} N_{w}(0)^{\frac{\alpha}{\sigma-1}}\left(\frac{\sigma-1}{\beta \sigma}\right)
$$

We adopt Charlot et al's (2006) approach which applies different welfare approaches to Krugman's (1991) Core-periphery model to compare agglomeration and dispersion outcomes. In our case, we propose to discuss and compare optimality of outcomes obtained with and without subsidy policy using four different welfare criteria. Moreover, as was previously mentioned, these comparisons will be made according to different levels of economic integration. Unfortunately, and contrary to Charlot et al. (2006), given the complexity of the model, we will be obliged to use simulations. Among the four criteria, three are classical welfare criteria (Bentham, Rawls and Pareto) which define the notion of optimality in very different ways. For instance, the Bentham criterion only takes global welfare into account which implies (for the government) choosing $T$ which maximizes the sum of national welfares:

$$
\max _{T} W=V_{a}(T)+V_{b}(T)
$$

The Rawls criterion focuses on the improvement of the poorest consumer's situation which implies choosing $T$ and thereby maximizing the welfare of the poorest representative consumer:

$$
\max _{T} W=\min \left[V_{a}(T), V_{b}(T)\right]
$$

Contrary to the Bentham criterion, the Pareto criterion focuses upon individual welfare. The optimum is defined as a situation where the government is not able to improve the situation of one agent without reducing the welfare of others. In our model, it implies choosing $T$ which maximizes the welfare in country $b$ for a given value of welfare in country $a$ :

$$
\begin{array}{ll}
\max _{T} & V_{b}(T) \\
\text { s.t } & V_{a}(T)=V_{a}^{*}
\end{array}
$$

If these three criteria define different optimum concepts, each of them only considers one specific aspect in the sense that Betham considers only global welfare, Rawls only the welfare of the poorest agent and Pareto only individual welfare. We therefore propose to refine the Bentham criterion in order to take global as well as individual aspects into account. This fourth criterion, that we will call, the Individually Constrained Bentham (ICB) criterion, defines as optimum, the situation where global welfare is as high as possible with the constraint that individual welfare is at least as high as in the free market equilibrium outcome. According to this criterion, the government will choose $T$ which maximizes global 
welfare given the constraint that individual welfare in each country has to be, at least, at the same level as in the case where the policy is not implemented:

$$
\begin{array}{cc}
\max _{T} & W=V_{a}(T)+V_{b}(T) \\
\text { s.t } & V_{a}(T) \geq V_{a}(0) \\
& V_{b}(T) \geq V_{b}(0)
\end{array}
$$

\subsection{Effects of the innovation subsidy policy on the consumer's welfare}

In order to grasp the different impacts of the innovation subsidy policy upon the consumer's welfare, we will analyze the derivative of expressions (30) and (31) with respect to $T$ :

$$
\begin{aligned}
& \frac{d V_{a}}{d T}=\underbrace{\frac{\alpha}{\rho(\sigma-1)} \frac{(1-\phi)}{\left(s_{n}(1-\phi)+\phi\right)} \frac{d s_{n}}{d T}}_{\text {transport cost effect }}+\underbrace{\frac{1}{\rho} \frac{d \log E_{a}}{d T}}_{\text {wealth effect }}+\underbrace{\frac{\alpha}{\rho^{2}(\sigma-1)} \frac{d g}{d T}}_{\text {growth effect }} \\
& \frac{d V_{b}}{d T}=\underbrace{-\frac{\alpha}{\rho(\sigma-1)} \frac{(1-\phi)}{\left(1-s_{n}(1-\phi)\right.} \frac{d s_{n}}{d T}}_{\text {transport cost effect }}+\underbrace{\frac{1}{\rho} \frac{d \log E_{b}}{d T}}_{\text {wealth effect }}+\underbrace{\frac{\alpha}{\rho^{2}(\sigma-1)} \frac{d g}{d T}}_{\text {growth effect }}
\end{aligned}
$$

The first term of expressions (32) and (33) or the transport cost effect refers to the impact of the tax rate upon the consumer's welfare via its effect upon the location of manufacturing firms. Indeed, it should be remembered that an increase of the tax rate reduces income inequality and leads to a delocation of some M-firms from country $a$ to country $b$. Therefore, consumers from country $b$ will save the transport cost on the goods produced by M-firms that move whereas the opposite occurs in country $a$. This explains why the transport cost effect is negative for country $a$ and positive for country $b$. It should also be noted that in absolute value, the impact of the transport cost effect is lower for country $a$ than for country $b$. In other words, the transport cost effect is positive according to the Bentham criterion; the reason being that the movement of $\mathrm{M}$-firms which affects the price index in each region is lower in country $a$ than in country $b$ in absolute value, i.e, the increase of the price index in region $a$ is lower than the decrease of the price index in region $b$.

The second term of expressions (32) and (33) or the wealth effect refers to the impact of the tax rate upon the consumer's welfare via its effect on nominal income. It should be remembered that the value of knowledge capital decreases with the level of subsidies, see (23), and that a higher tax rate will raise the level of subsidies. An increase in the tax rate will therefore reduce the nominal income in both countries but the effect will be stronger in the richer country $(a)$ as a more important part of the total income is related to capital income. To summarize, the wealth effect is negative because it reduces the nominal income in both countries but the effect is stronger in the richer country. 
The third term of expressions (32) and (33) or the growth effect refers to the impact of the tax rate upon the consumer's welfare via its effect on the growth rate. As demonstrated by Montmartin (2010), in most cases, public policy will increase the aggregate growth rate. A higher growth rate corresponds to a stronger creation dynamic of industrial activities so that at each period the number of M-firms increases. This greater dynamic will lead to a decrease of price indexes in both regions and hence to an increase of real incomes. This explains why the growth effect is positive.

In short, the innovation subsidy policy affects the consumer's welfare by three vectors. Firstly, say the wealth effect decreases welfare in both countries because it reduces nominal income. Secondly, the growth effect increases welfare in both countries because it raises the real income. Finally, the transport cost effect is positive for consumers located in country $b$ as opposed to those located in country $a$ as the innovation policy leads to a delocation of industrial activities from country $a$ to country $b$. The innovation subsidy policy will therefore have a higher positive impact upon the consumer's welfare in the poorer country, say country $b$.

\subsection{Optimality of the subsidy policy}

In this sub-section, we will analyze the optimality of the innovation subsidy policy according to the various welfare criteria defined previously and various levels of economic integration. The value of parameters used for the simulations presented below are based upon those of Martin and Ottaviano (1996). ${ }^{14}$ Moreover for technical reasons ${ }^{15}$, we restrict the definition domain of $T$ from $[0,1[$ to $[0,0.99[$.

\subsubsection{The case of low international knowledge spillovers}

Here, we will investigate the optimality of the innovation subsidy policy in an economy characterized by very limited knowledge integration (we suppose that $\lambda=0.1$ ). If we fix the value of international knowledge spillovers, the figures below represent the evolution of the welfare in each country and in the whole economy for different levels of trade integration. We will then denote the optimal tax rates as $T_{x}^{*}$ where $x$ is the abreviation of the welfare criterion retained ( $P$ for Pareto, $R$ for Rawls, $B$ for Bentham and $I C B$ for our welfare criterion).

\footnotetext{
${ }^{14}$ More precisely the values of the parameters used are : $\alpha=0.5, \sigma=3, \rho=0.1, L=$ 0.4 , and $s_{k}=0.7$

${ }^{15}$ Indeed, in some cases welfare increases with the tax rate, so that there is no optimal policy. It is necessary to impose this restriction if we are to systematically obtain an optimal tax rate.
} 




Figure 3a : Evolution of welfare in region $a$

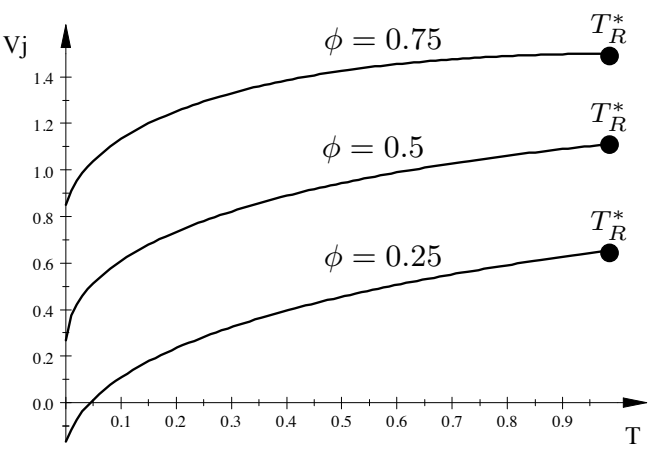

Figure $3 \mathrm{~b}$ : Evolution of welfare in region $b$

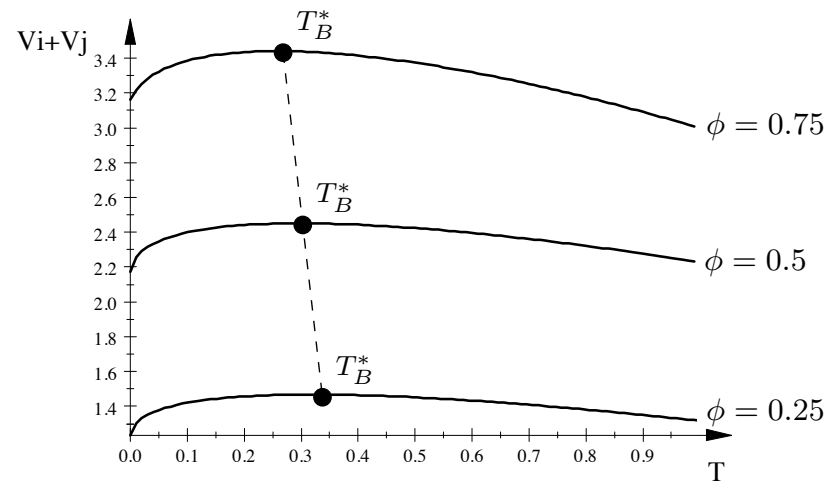

Figure 3c: Evolution of global welfare

We can see in figures $3 a$ and $3 b$ that an increase in the tax rate (whatever the level of trade integration) has a conflicting effect upon consumer welfare. Indeed, whereas the tax rate raises the consumer's welfare in country $b$, the consumer's welfare in country $a$ decreases along with the tax rate. Consequently, all tax rates in $[0,0.99]$ are Pareto-optimal, i.e, the government cannot improve welfare in one country without reducing welfare in the other country. According to the Rawls criterion, the government should implement the largest possible subsidy policy $\left(T_{R}^{*}=0.99\right)$ whereas according to the ICB criterion, the government should not implement the innovation subsidy policy $\left(T_{B I C}^{*}=0\right)$. Two reasons explain the conflicting effect of the subsidy policy. Firstly, the transport cost effect is positive for region $b$ whereas it is negative for region $a$ (see 4.1.2). Secondly, the growth effect which is positive for both regions decreases in $\lambda$, i.e, the level of international knowledge spillovers. It should be remembered that the subsidy policy leads to a more dispersed geography of industrial activities which reduces $R \& D$ productivity and limits the positive effect of this policy upon growth. We 
show in appendix $C$ that the lower the international knowledge spillovers, the higher the cost (in terms of growth reduction) of delocation of industrial activities towards the poorer region. We can therefore express the following proposition:

Proposition 1: Consider an economy composed of two countries with different levels of wealth. If the international knowledge spillovers are low then a centralized subsidy policy for R\&D employment has a positive (negative) effect upon the welfare of consumers located in the poorer (richer) country. There therefore exists a conflict of interest between these countries.

As we can see in figure $3 c$, the Bentham-optimal tax rate does not correspond to an extreme value of tax rate as it does for the other criteria. This figure highlights a very interesting result. Indeed, the Bentham-optimal tax rate decreases with the level of trade integration whereas this is not the case for the other criteria. This means that the government's optimal intervention (according to this criterion) should decrease in a context of increasing trade integration. The reason for this result is that the higher the level of trade integration, the higher the impact of the tax rate upon the delocation of industrial activities (see proof in appendix C). Combining this with the fact that the delocation cost (in terms of growth reduction) of industrial firms is higher for a low value of international knowledge spillovers, it would appear logical that the level of the Bentham-optimal tax rate decreases with the level of trade integration.

\subsubsection{The case of an intermediate level of international knowledge} spillovers

Here, we will investigate the optimality of the innovation subsidy policy in an economy characterized by an intermediate level of knowledge integration (we suppose that $\lambda=0.4$ ). As before, the figures below represent the evolution of welfare in each region and within the whole economy for different levels of trade integration.

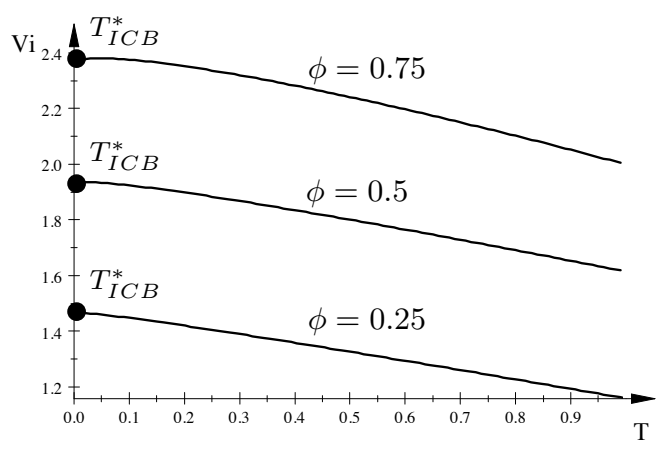

Figure 4a : Evolution of welfare in region $a$



Figure 4b : Evolution of welfare in region $b$ 


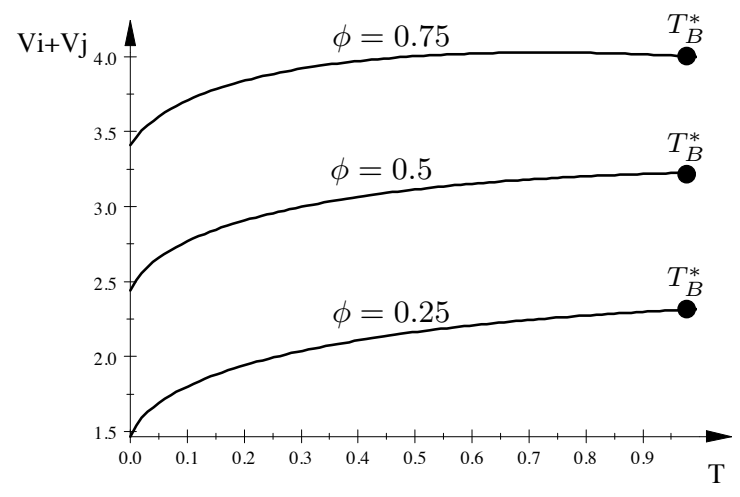

Figure 4c : Evolution of global welfare

If we compare these figures with the previous ones, it appears that we have the same result concerning the national consumer's welfare. Indeed, the consumer's welfare in the richer country decreases with the tax rate whereas it increases in the poorer country (whatever the level of trade integration). We could therefore extend Proposition 1 to the case where international knowledge spillovers are at an intermediate level. Indeed, as in the previous case, according to the ICB criterion, the government should not implement the innovation subsidy policy $\left(T_{I C B}^{*}=0\right)$ whereas according to the Rawls criterion, the government should implement the largest possible subsidy policy $\left(T_{R}^{*}=0.99\right)$. Note also that all tax rate values are Pareto-optimal because the government cannot increase the welfare in one country without reducing it in the other. Finally, the only difference with the case where international knowledge spillovers are low is the Bentham-optimal level of tax rate. Indeed, as we can see in figure 4c, the Bentham-optimal level of tax rate corresponds to the Rawls-optimal level of tax rate whatever the level of trade integration. Therefore, according to the Bentham criterion, the government should implement a wider public policy when knowledge spillovers are less localized; the reason being that when knowledge spillovers are less localized, the delocation cost (in terms of growth reduction) of industrial activities towards the poorer region is less important. The fact that the Bentham-optimal tax rate is defined by $T_{B}^{*}=0.99$ means that the welfare loss of consumers in the richer country is more than compensated by the welfare gain for consumers in the poorer country.

\subsubsection{The case of high international knowledge spillovers}

Here, we investigate the optimality of the innovation subsidy policy in an economy characterized by a high level of knowledge integration (we suppose that $\lambda=0.7$ ). As before, the figures below represent the evolution of welfare in each country and in the whole economy for different levels of trade integration. 


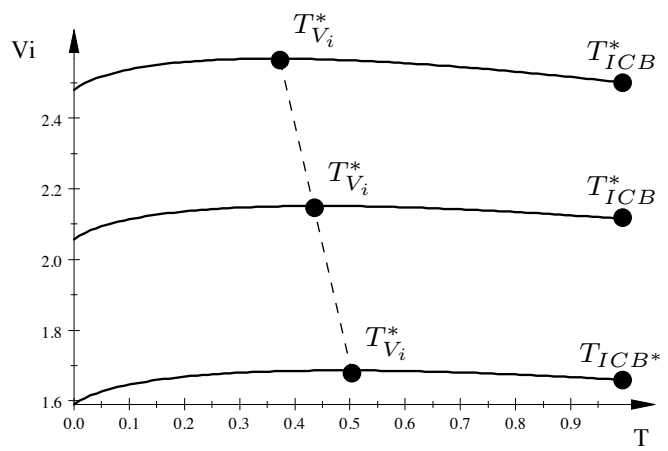

Figure 5a : Evolution of welfare in region $a$

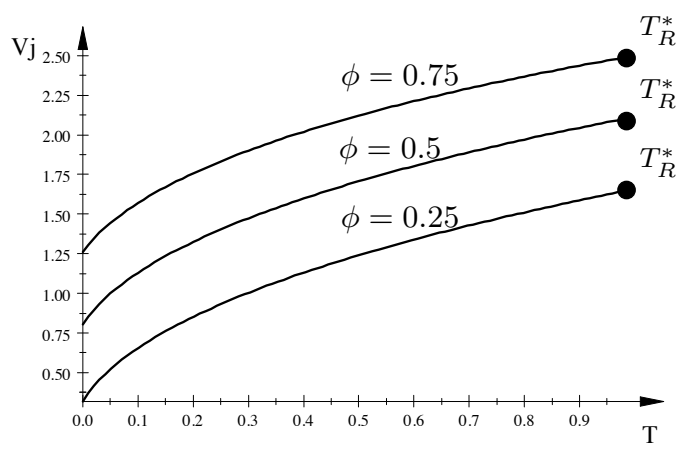

Figure 5b : Evolution of welfare in region $b$

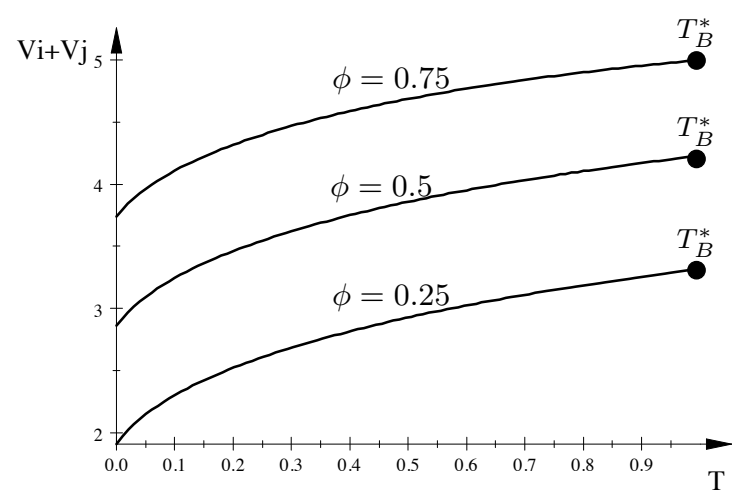

Figure 5c: Evolution of global welfare

Contrary to previous cases, when international knowledge spillovers are relatively high, the consumer's welfare in country $a$ does not decrease with the tax rate as we can see in figure 5a. Indeed, the tax rate has a positive (but not continuous) impact upon the welfare in country $a$. From 0 to $T_{V_{i}}^{*}$, which represents the tax rate that maximizes the consumer's welfare in country $a$, welfare increases. From $T_{V_{i}}^{*}$ to $T_{I C B}^{*}$ welfare decreases but still remains higher than without a subsidy policy. Therefore, all taxes rates between $T_{V_{i}}^{*}$ and $T_{I C B}^{*}$ are Pareto-optimal. It should also be noted that the tax rate which maximizes consumers' welfare in region $a$ decreases with the level of trade integration; the reason being that the higher the level of trade integration, the higher the impact of the tax rate upon the delocation of manufacturing firms. Therefore, ceteris paribus, the consumers located in country $a$ lose more welfare because more firms move to the poorer country so that they then have to consume more imported varieties. We can also note that the consumer's welfare in region $b$ increases 
with the tax rate when knowledge spillovers are geographically well transmitted. Hence, we can express the following proposition:

Proposition 2: Consider an economy composed of two countries with different levels of wealth. If the international knowledge spillovers are high then a centralized subsidy policy to R\&D employment can improve welfare in both countries. Therefore, the implementation of the policy does not lead to a conflict of interest between countries.

Consequently, it will be easier for the central authority to implement an innovation subsidy policy in this case. This is due to the fact that in an economy with high international knowledge spillovers, the geography of industrial activities matters less for growth. Indeed, the negative impact of the subsidy policy on the consumer's welfare in country $a$ via the delocation of a part of industrial firms is less important whereas its positive impact via the growth rate is more significant.

When international knowledge spillovers are high, welfare analysis highlights a very interesting configuration. Indeed, in this case, the optimal tax rate according to our four different criteria could correspond to the same value, i.e, $T_{I C B}^{*}=$ $T_{P}^{*}=T_{B}^{*}=T_{R}^{*}$. Indeed, according to the ICB, Bentham and Rawls criteria, the optimal level of tax rate is $T=0.99$. According to the Pareto criterion, $T=0.99$ corresponds to one optimum (but it is not the only one). The positive effect of a centralized innovation policy is clearly apparent in this case.

\section{Concluding Remarks}

In this paper, our objective was to provide new elements to explain the difficulty of establishing a real innovation policy at the European level. To this end, we have used an agglomeration and growth model à la Martin and Ottaviano (1999) into which we have introduced a central government which is able to implement a subsidy policy for R\&D employment. Previous works by Martin (1999) and Montmartin (2010) have shown that an innovation subsidy policy which does not change the geography of innovation is able to simultaneously increase the efficiency and the equity of the economy. We show in this paper however, that if we analyze the impact of this policy in terms of welfare, the results are more contrasting. Indeed, we have seen that this innovation policy, in an economy composed of two countries with different levels of wealth, could have opposite effects on the consumer's welfare, depending upon the country. More specifically, our results suggest that, if the international knowledge spillovers are not strong then the implementation of an innovation subsidy policy leads to a conflict of 
interest between regions in the sense that the welfare of consumers in the richer country decreases whereas that of those in the poorer country increases. Our result can therefore be viewed as an explanation for the difficulties involved in implementing centralized innovation policies at the European level. Indeed, it will be harder to implement centralized policies in an economic union if some countries suffer from it (especially if they are the policy's main backers). We think that this result might also be relevant when explaining why richer countries in the European Union, such as Germany, France or the United Kingdom are so critical of the policies implemented by the European Union, especially the Regional Policy. It should be noted that this result supposes that international knowledge spillovers are not really strong between countries. One might easily think that this is still the case in the European Union due to the many knowledge transfer barriers. Some of these are related to the properties of knowledge, like tacitness and some of them are specific to the European Union, like the low mobility of workers or the cultural, social and technological distance.

The welfare analysis also highlights the central role played by the diffusion of knowledge among countries on the optimality of the policy. Indeed, we have seen that the conflicts of interest between countries involved in the implementation of the innovation policy disappears when international knowledge spillovers are strong. In our model, the spatial dimension of knowledge spillovers is a key feature because it directly affects the productivity of $R \& D$ activities and the cost of delocation industrial activities. More specifically, the higher the spatial diffusion of knowledge, the higher the R\&D productivity and the lower (in terms of growth reduction) the cost of delocation industrial firms. Therefore, our model suggest that it would be simpler and more efficient to implement an innovation subsidy policy in an economic union in which countries can benefit from knowledge produced in the others. In other words, in the European context, this result means that before directly subsidizing R\&D activities, the european authorities should strengthen and develop the knowledge flows between European countries. A number of public policies could contribute to the development of knowledge flows, such as investment in ICT technologies, investment in human capital (by developing the education and people's absorption capacity) as well as all public policies that can improve or facilitate the mobility of workers within the economy. It should be noted however, that some european R\&D policies try to improve knowledge diffusion within the European Union. We especially think of the Framework Programs which aim to strenghthen cooperations at the European level and the mobility of researchers, although their effects are difficult to measure (given the importance of national policies).

If knowledge integration strengthens the positive effects of an innovation subsidy policy, it would seem that trade integration plays an opposite although less important role. Indeed, in welfare analysis, we have seen that the optimal tax rates decreases with the level of trade integration, i.e, government intervention 
should decrease with the level of trade integration. The reason for this is that the higher the level of trade integration, the higher the impact of the tax rate on the delocation of industrial activities towards the poorer region (see appendix C). As R\&D productivity and the growth rate are positively correlated with the concentration of $\mathrm{M}$-firms in the richer region, an increase of trade integration will increase the negative impact of the subsidy policy. To conclude, our results suggest that (1) contrary to knowledge integration, trade integration reduces the effectiveness of a centralized subsidy policy and (2) the optimal level of subsidy depends more upon the level of knowledge integration than upon the level of trade integration.

\section{Acknowledgements}

I wish to thank Nadine Massard and Stephane Riou for providing numerous suggestions that have substantially improved the article. I have also benefited from comments of participants at the $4^{\text {th }} \mathrm{J} 2 \mathrm{E}$ (Conference "Economics and Space"), organized by INRA-SMART, Rennes and I specially thank JacquesFrançois Thisse, Kristian Behrens, Carl Gaigné, Nelly Exbrayat and Fabien Candau.

\section{Appendix}

\section{Appendix A}

The equilibrium location of manufacturing firms has to satisfy the condition given by (29). We can rewrite (29) as a third degree polynomial function of $s_{n}$ : $f\left(s_{n}\right)=a s_{n}{ }^{3}+b s_{n}{ }^{2}+c s_{n}+d=0$ with

$$
\begin{gathered}
a=-8 L \alpha \sigma \rho(1-\lambda)(1-T) \\
b=-4 L \alpha \rho(1-T) \frac{L \alpha(1+\phi)(1-\lambda)\left(1-2 s_{k}\right)+\sigma(1-\phi)[\rho+2 L(2 \lambda-1)]}{(1-\phi)} \\
c=\frac{2 \alpha \rho(1-T)\left[\left(1-2 s_{k}\right)(1+\phi)(L \alpha(1-3 \lambda)-\rho \alpha(1-T))\right]}{1-\phi} \\
+\frac{2 \alpha \rho(1-T)\left[\rho \sigma\left(1-3 \phi+2 s_{k}(1+\phi)\right)-L \sigma(1-\phi)(1-5 \lambda)\right]}{1-\phi}
\end{gathered}
$$




$$
\begin{aligned}
d & =\frac{2 \alpha \rho(1-T)}{(1-\phi)^{2}} L \lambda(1-\phi)\left[\alpha(1+\phi)\left(1-2 s_{k}\right)-\sigma(1-\phi)\right] \\
& +\frac{2 \alpha \rho(1-T)}{(1-\phi)^{2}} \rho\left(s_{k}-\phi\left(1-s_{k}\right)\right)\left[\alpha(1+\phi)\left(1-2 s_{k}\right)(1-T)-\sigma(1-\phi)\right]
\end{aligned}
$$

There are three real solutions to such an equation but by using expression (29) and simulations, we can easily see that only one is available. This solution is given by:

$$
s_{n}=2 \sqrt{-\frac{p}{3}} \cos \left(\frac{\arccos \left(\frac{3 q}{2 p} \sqrt{-\frac{3}{p}}\right)+4 \pi}{3}\right)-\frac{b}{3 a}
$$

with

$$
\begin{gathered}
p=\frac{c}{a}-\frac{b^{2}}{3 a^{2}} \\
q=\frac{d}{a}+\frac{b}{27 a}\left(\frac{2 b^{2}}{a^{2}}-\frac{9 c}{a}\right)
\end{gathered}
$$

It should be noted that when $T=0$, the concentration of the industrial sector in the richer country is complete $\left(s_{n}=1\right)$ when the degree of trade integration exceeds the threshold level:

$$
\phi^{*}=\frac{L+\rho(1-k)}{L+\rho k}
$$

\section{Appendix B}

In this appendix, we demonstrate the effect of the subsidy policy upon the equilibrium outcome, i.e, the impact of an increase of the tax rate upon the three equilibrium variables $\left(s_{n}, s_{e}, g\right)$.

\section{Sign of the derivative of $s_{n}$ with respect to $T$}

Using (14), (26) and (28), the derivative of $s_{n}$ with respect to $T$ is given by:

$$
\frac{d s_{n}}{d T}=\left(\frac{\partial s_{n}}{\partial s_{e}} \frac{\partial s_{e}}{\partial g} \frac{\partial g}{\partial T}+\frac{\partial s_{n}}{\partial s_{e}} \frac{\partial s_{e}}{\partial T}\right)\left(1-\frac{\partial s_{n}}{\partial s_{e}} \frac{\partial s_{e}}{\partial g} \frac{\partial g}{\partial s_{n}}\right)^{-1}
$$

With the same expressions as are used above, we can calculate the following partial derivatives: 


$$
\begin{gathered}
\frac{\partial s_{n}}{\partial s_{e}}=\frac{1+\phi}{1-\phi}>0 \quad \frac{\partial s_{e}}{\partial g}=-\frac{\alpha \rho\left(2 s_{k}-1\right)(1-T)}{2 \sigma(g+\rho)^{2}}<0 \\
\frac{\partial g}{\partial T}=\frac{\alpha \rho}{2 \sigma}\left(\frac{4 A L \sigma-g}{\sqrt{\Lambda^{2}+8 A L T \alpha \sigma \rho}}\right)>0 \quad \frac{\partial s_{e}}{\partial T}=-\frac{\alpha \rho\left(2 s_{k}-1\right)}{2 \sigma(g+\rho)}<0 \\
\frac{\partial g}{\partial s_{n}}=\frac{L \alpha(1-\lambda)}{\sigma}\left(\frac{g+2 T \sigma \rho}{\sqrt{\Lambda^{2}+8 A L T \alpha \sigma \rho}}\right)>0
\end{gathered}
$$

with

$$
\Lambda=\alpha[2 A L-\rho T]-\rho(\sigma-\alpha)
$$

Using signs of these partial derivatives, we see immediately that an increase of the tax rate will reduce the spatial concentration of manufacturing firms in the richer country, i.e, $d s_{n} / d T<0$.

\section{Sign of the derivative of $g$ with respect to $T$}

Consider now the derivatives of the growth rate (26) and the income inequality (28) with respect to $T$. These are given by:

$$
\begin{aligned}
& \frac{d g}{d T}=\frac{\partial g}{\partial T}+\frac{\partial g}{\partial s_{n}} \frac{d s_{n}}{d T} \\
& \frac{d s_{e}}{d T}=\frac{\partial s_{e}}{\partial T}+\frac{\partial s_{e}}{\partial g} \frac{d g}{d T}
\end{aligned}
$$

Inserting (37) in (36), we can rewrite (36) as :

$$
\frac{d g}{d T}=\left(\frac{\partial g}{\partial T}+\frac{\partial g}{\partial s_{n}} \frac{\partial s_{n}}{\partial s_{e}} \frac{\partial s_{e}}{\partial T}\right)\left(1-\frac{\partial s_{n}}{\partial s_{e}} \frac{\partial s_{e}}{\partial g} \frac{\partial g}{\partial s_{n}}\right)^{-1}
$$

Using signs of the partial derivatives, we know that the second term of this expression is positive so the sign of $d g / d T$ depends upon the sign of the first term. Using expressions of partial derivatives, we obtain:

$$
\left(\frac{\partial g}{\partial T}+\frac{\partial g}{\partial s_{n}} \frac{\partial s_{n}}{\partial s_{e}} \frac{\partial s_{e}}{\partial T}\right)=A B
$$

with

$$
\begin{gathered}
A=\frac{\alpha \rho}{\sigma(1-\phi)(g+\rho)} \\
B=\frac{\sigma(1-\phi)(g+\rho)(2 A L-g)-L \alpha(1+\phi)(1-\lambda)\left(2 s_{k}-1\right)(g+T \rho)}{\sqrt{\Lambda^{2}+8 A L T \alpha \sigma \rho}}
\end{gathered}
$$


$A$ is positive and the denominator of $B$ is also positive so we know that $\operatorname{sign}(d g / d T)=\operatorname{sign}(B)$. It should be noted that without subsidy policy, all Mfirms are concentrated in the richer region when $\phi \geq \phi^{*}$ (see the end of appendix A). So by replacing $\phi$ with $\phi^{*}$, we obtain:

$$
\frac{d g}{d T}>0 \quad \text { if } \quad \frac{\sigma(g+\rho) \rho\left(2 A_{i} L-g\right)}{L \alpha(1-\lambda)(2 L+\rho)(g+T \rho)}>1
$$

Solving this second degree inequality in $g$, we obtain:

$$
\frac{d g}{d T}>0 \quad \text { if } g<g^{*}=\frac{\Upsilon+\sqrt{\Upsilon^{2}+4 L \sigma \rho^{2}[2 A \sigma \rho-T \alpha(1-\lambda)(2 L+\rho)]}}{2 \sigma \rho}
$$

with

$$
\Upsilon=\sigma \rho(2 A L-\rho)-L \alpha(1-\lambda)(2 L+\rho)
$$

Note that if we prove that $\rho \Lambda<\Upsilon$ then $g<g^{*}$. Indeed, the condition $\rho \Lambda<\Upsilon$ is more restrictive than $g<g^{*}$ and corresponds to:

$$
\rho \alpha[2 A L-\rho T]-\rho^{2}(\sigma-\alpha)<\sigma \rho(2 A L-\rho)-L \alpha(1-\lambda)(2 L+\rho)
$$

which is equivalent to

$$
s_{n}>s_{n}^{*}=\frac{1}{2}-\frac{L \sigma \rho(1+\lambda)-2 L \alpha[L(1-\lambda)+\rho]-\alpha \rho^{2}(1-T)}{2 L \rho(1-\lambda)(\sigma-\alpha)}
$$

We are sure that $s_{n}>s_{n}^{*}$ if $L \sigma \rho(1+\lambda)-2 L \alpha[L(1-\lambda)+\rho]-\alpha \rho^{2}(1-T)>0$. This condition is satisfied when

$$
\lambda>\lambda^{*}=\frac{2 L \alpha(L+\rho)+\alpha \rho^{2}(1-T)-L \sigma \rho}{L(2 L \alpha+\sigma \rho)}
$$

If this condition on $\lambda$ is verified, then an increase of the tax rate will increase the aggregate growth rate. Note that this condition is the strongest possible constraint, i.e, for extreme value of $\phi$ and $s_{n}$. So in most cases the constraint is less strong than (38).

\section{Sign of the derivative of $s_{e}$ with respect to $T$}

The sign of $d s_{e} / d T$ is more easily to determined than for $d g / d T$. We could work with (38) to determine the sign of $d s_{e} / d T$ but we can determine it more easily by considering the following expression:

$$
\frac{d g}{d T}=\left(\frac{\partial g}{\partial T}+\frac{\partial g}{\partial s_{n}} \frac{\partial s_{n}}{\partial s_{e}} \frac{\partial s_{e}}{\partial T}\right)\left(1-\frac{\partial s_{n}}{\partial s_{e}} \frac{\partial s_{e}}{\partial g} \frac{\partial g}{\partial s_{n}}\right)^{-1}
$$

Inserting expression (38) in this expression, we get

$$
\frac{d g}{d T}=\frac{\partial g}{\partial T}+\frac{\partial g}{\partial s_{n}} \frac{\partial s_{n}}{\partial s_{e}} \frac{d s_{e}}{d T}
$$


If we compare this expression with (37), we can see that the following equality holds:

$$
\frac{d s_{n}}{d T}=\frac{\partial s_{n}}{\partial s_{e}} \frac{d s_{e}}{d T}
$$

As $\partial s_{n} / \partial s_{e}>0$ and $d s_{n} / d T<0$, we know that $d s_{e} / d T<0$, i.e, an increase of the tax rate will lead to a decrease of the income inequality between countries. This proves that even if we consider extreme cases where $\lambda<\lambda^{*}$, i.e, even if an increase of the tax rate reduces the growth rate, it reduces the income inequality. Therefore, for realistic cases where the subsidy policy increases the growth rate, the decrease of income inequality is stronger.

We can also determine the effect of an increase of the tax rate upon the Home Market Effect. Indeed, expression (39) shows that the higher the tax rate the lower is the Home Market Effect. The reason for this is simply that $\partial s_{n} / \partial s_{e}>1$, so an increase of the tax rate will decrease the concentration of M-firms more than the income inequality.

\section{Appendix C}

Proof 1: the lower the knowledge spillovers, the higher the cost (in terms of growth reduction) of delocation of industrial activities towards the poorer region

For this purpose, we have to calculate the partial derivative of $\partial g / \partial s_{n}$ with respect to $\lambda$. Using expression of $\partial g / \partial s_{n}$ (see appendix B), we have:

$$
\begin{aligned}
\frac{\partial\left(\frac{\partial g}{\partial s_{n}}\right)}{\partial \lambda}= & -4 L^{2} \alpha^{2}(1-\lambda)(g+T \rho)\left(1-s_{n}\right)\left(\frac{(\Lambda+2 T \sigma \rho)}{\left(\sqrt{\Lambda^{2}+8 A L T \alpha \sigma \rho}\right)^{3}}\right) \\
& -L \alpha\left(\frac{2(g+T \rho)}{\sqrt{\Lambda^{2}+8 A L T \alpha \sigma \rho}}\right)<0
\end{aligned}
$$

This result shows that a decrease of $\lambda$ will increase $\partial g / \partial s_{n}$. It should be remembered that

$$
\frac{d g}{d T}=\frac{\partial g}{\partial T}+\frac{\partial g}{\partial s_{n}} \frac{d s_{n}}{d T}
$$

As $d s_{n} / d T<0$, the lower the knowledge spillovers, the higher the cost (in terms of lost growth) of delocation of industrial activities towards the poorer country.

Proof 2: the higher the level of trade integration, the higher the impact of the tax rate upon the delocation of industrial activities 
To do this, we have to calculate the partial derivative of $d s_{n} / d T$ with respect to $\phi$. Using expression (35) and the expressions of partial derivatives given in Appendix $B$, we can rewrite:

$$
\frac{d s_{n}}{d T}=\frac{-\frac{\alpha \rho\left(2 s_{k}-1\right)}{\sigma(g+\rho)}\left(\frac{\alpha \rho(1-T)}{(g+\rho)}\left(\frac{2 A L-g}{\sqrt{\Lambda^{2}+8 A L T \alpha \sigma \rho}}\right)+1\right)}{\frac{2(1-\phi)}{(1+\phi)}+\frac{2 \alpha^{2} \rho L(1-\lambda)\left(2 s_{k}-1\right)(1-T)}{\sigma(g+\rho)^{2}}\left(\frac{g+T \rho}{\sqrt{\Lambda^{2}+8 A L T \alpha \sigma \rho}}\right)}
$$

This expression has the form:

$$
\frac{d s_{n}}{d T}=\frac{X}{\frac{2(1-\phi)}{(1+\phi)}+Y}
$$

where $X<0$ and $Y>0$. The partial derivative of $d s_{n} / d T$ with respect to $\phi$ has the form:

$$
\frac{\partial\left(\frac{d s_{n}}{d T}\right)}{\partial \phi}=\frac{4 X}{[Y(1+\phi)+2(1-\phi)]^{2}}<0
$$

This result means that the higher the level of trade integration, the higher the impact of the tax rate upon the delocation of industrial activities.

\section{References}

[1] Baldwin R. \& Martin P. (2004), "Agglomeration and Regional Growth", in Vernon Henderson J. \& Thisse J-F., Handbook of Regional and Urban Economics, vol.4 Cities and Geography, chap. 60, p. 2670-2711

[2] Baldwin R., Forslid R., Martin P., Ottaviano G. \& Robert-Nicoud F. (2003), "Economic Geography and Public Policy ", Princeton University Press

[3] Barro R. \& Sala-I-Martin X. (1996), "La croissance économique", Ediscience / McGraw-Hill, Collection sciences Economiques

[4] Besley T. \& Coate (2003), "Centralized versus decentralized provision of local public goods: a political economy approach", Journal of Public Economics, $\mathrm{n}^{\circ} 87, \mathrm{p} .2611-2637$

[5] Begg I., Hodson D. \& Maher I. (2003), "Economic policy coordination in the European Union", National Institute Economic Review, n ${ }^{\circ} 83$, p.66-77 
[6] Brehon N-J. (2010), "Le budget europeéen: quelle négociation pour le prochain cadre financier de l'Union européenne?", Questions d'Europe, n 170 171, Fondation Robert Schuman

[7] Buiter W. \& Kletzer K. (1992), "Fiscal policy coordination as fiscal federalism", European Economic Review, n³6, p.647-653

[8] Casella A. (2005), "Redistribution policy: A European model", Journal of Public Economics, vol. 89, p. 1305-1331

[9] Charlot S., Gaigné C., Robert-Nicoud F. \& Thisse J-F. (2006), "Agglomeration and welfare: The core-periphery model in the light of Bentham, Kaldor and Rawls", Journal of Public Economics, vol.90, p.325-347

[10] Chu A. (2009), "A politico-economic analysis of the European Union's R\&D policy", Journal of Macroeconomics, $n^{\circ} 31$, p.582-590

[11] D'Aspremont C. \& Jacquemin A. (1987), "Cooperative and Noncooperative R\&D in Duopoly with Spillovers", American Economic Review, vol.78, $\mathrm{n}^{\circ} 5, \mathrm{p} .1133-1137$

[12] Feldman M. (2000), "Location and Innovation: The New Economic Geography of Innovation, Spillovers, and Agglomeration", in Clark G., Feldman M. \& Gertler M., The Oxford Handbook of Economic Geography, chap. 19, p.373-394

[13] Fuest C. \& Huber B. (2006), " Can regional policy in a federation improve economic efficiency?", Journal of Public Economics, vol. 90, p.499-511

[14] Glaeser E., Kallal H., Scheinkman J. \& Schleifer A. (1992), "Growth in Cities", Journal of Political Economy, vol.100, n6, p.1126-1152

[15] Grossman G. \& Helpman E. (1991), "Innovation and Growth in the Global Economy", MIT Press, Cambridge CA

[16] Haaland J. \& Kind H. (2006), "Cooperative and Non-Cooperative R\&D Policy in an Economic Union", Review of World Economics vol. 142, $n^{\circ} 4$, p.720745

[17] Jones C. \& Williams (2000), "Too Much of a Good Thing? The Economics of Investment in R\&D", Journal of Economic Growth, vol.5, p.65-85

[18] Krugman P. (1991), "Increasing Returns and Economic Geography", Journal of Political Economy, n 99, p.483-499 
[19] Martin P. \& Ottaviano G. (1996), "Growth and Agglomeration" , Document de travail $n^{\circ} 96-14$, CEPII

[20] Martin P. \& Ottaviano G. (1999), "Growing locations: Industry Location in a Model of Endogenous Growth" , European Economic Review n³, p. 281302

[21] Martin P. (1999), "Public policies, regional inequalities and growth", Journal of Public Economics n ${ }^{\circ}$, p.85-105

[22] Maurseth P.B \& Verspagen B. (2002), "Knowledge Spillovers in Europe: A Patent Citations analysis", Scandinav Journal of Economics, ${ }^{\circ}{ }^{104}$, p.531-545

[23] Mesclier, F. (2007), "Politique régionale européenne: Vers une remise en cause de l'objectif de convergence", L'Harmattan, Collection Inter-national

[24] Montmartin B. (2010), "Subsidy Policy to Innovation: A way to reach objectives of both higher growth and equity?", Working Paper du GATE Lyon Saint-Etienne 2010 Vol. 31

[25] Musgrave, R. (1959), "The Theory of Public Finance", New York, Mc Graw Hill

[26] Oates W. (1972), "Fiscal federalism", New York, Harcourt, Brace, Jovanovitch

[27] Oates W. (2005), "Toward a Second-Generation Theory of Fiscal Federalism", International Tax and Public Finance, $\mathrm{n}^{\circ} 12$, p.349-373

[28] Riou S. (2003), "How growth and location are sensitive to transport and telecommunications infrastructures", Recherches Economiques de Louvain, vol. 69 , p. $241-265$

[29] Rogers C. \& Martin P. (1995), "Industrial location and pulic infrastructure" , Journal of International Economics, n³9, p. 333-351

[30] Romer P. (1990), "Endogenous Technologocal Change", The Journal of Political Economy, vol. $98, n^{\circ} 5$, p.71-102

[31] Tiebout C.M. (1956), "A Pure Theory of Local Expenditures", Journal of Political Economy, n64, p.416-424 